\title{
An Analysis of Work Stress among College Teachers in Self- financing College, Perambalur District, Tamilnadu.
}

\author{
${ }^{1}$ Dr.M.Vasantha, ${ }^{2}$ Ms. R. Santhi, ${ }^{3}$.Ms. N. Deepalakshmi \\ ${ }^{1}$ Assistant Professor, Department of Commerce, Urumu Dhanalakshmi College, Trichy, \\ ${ }^{2}$ Assistant Professor, \\ \& Head, \& ${ }^{3}$ AssistanProfessor, \\ Department of Commerce, Dhanalakshmi Srinivasan College of Arts \& Science for Women, Perambalur
}

\begin{abstract}
Stress at the workplace is the major cause of most of the health problems. The study focus on an Analysis of Work Stress among College Teachers in Self-financing College, Perambalur District, Tamilnadu. The data collected from 50 respondents with the objectives of To find opinion about teaching and handling students, to find out the stress creators, to analysis of sharing stress problems, to find out techniques applied by the College teachers for managing stress.
\end{abstract}

\section{Introduction}

Life is not one dimensional but multidimensional. The quality of one's life depends on how an individual infuses quality in all aspects of life. Present-day life has become too complex and complicated. There is a scramble for more and more. A confused sense of affairs and lopsided values, that's leading to a lot of tension and distress. A positive personality possess free of negative elements like anxiety, stress, greed, envy and jealously. In various negative elements, stress can affect the human in various ways. Perfect health-and not disease - is the natural state of the human being. Most of us are born with perfect health. Disease is something that we acquire -without realising how-at various times throughout life. Stress appears to be the number one killer.

Families are breaking down under stress and most accidents are caused by stress. Anxiety attacks, phobias and depression are all stress related. Heart disease, diabetes, chronic fatigue, allergies, blood pressure and headaches are just a few of the commonly listed complaints that originate from stress. Stress is like a fire alarm within our body. Stress is the inability to cope with a real or imagines threat to one's mental, physical, emotional, and spiritual well-being which results in a series of physiological responses and adaptations. It can be caused by both good and bad experiences.

The level of stress is different for each one. It is an essential, rather a vital, ingredient for the normal functioning of the body and, hence, inescapable. It helps us in our survival on a sustained basis.

Stress cannot be avoided but, yes, it can be managed in a way that it does not become a source of trouble.

The term 'Stress" means many things to many a different people. Stress in terms of pressure, tension, unpleasant external forces or an emotional response. Stress is a subject which is hard to avoid. The concept of stress is something that involves biochemical, physiological behavioural and psychological changes. Stress mean hardship, strain, adversity, or affliction.

Stress can be a reaction to a short-lived situation, such as being stuck in traffic. Or it can last a long time if the person is dealing with relationship problems, a spouse's death or other serious situations. Stress becomes dangerous when it interferes with his ability to live a normal life over an extended period. The person may feel tired, unable to concentrate or irritable. Stress can also damage the person physical health.

Stress can precipitate or aggravate the experience of symptoms. People who are under stress may believe that they are more vulnerable to illness and so attend more closely to their bodies. Financial strain, disruptions in personal relationships, and other stressors lead people to believe that they are ill.

Stress has been examined in terms of psycho physiological changes. It increases in physical factors such as heart rate, blood pressure and muscle potential, changes in psychological factors, such as increases in fear, anxiety, anger and decreases in cognitive ability and sensitivity to others.

Stress is not always necessarily harmful. Hans Selye said in 1956, "stress is not necessarily something bad, it all depends on how you take it. The stress of exhilarating, creative successful work is beneficial, while that of failure, humiliation or infection is detrimental." Stress can be therefore negative, positive or neutral. Passing in an examination can be just stressful as failing.

Work-related stress is a growing problem around the world that affects not only the health and wellbeing of employees, but also the productivity of organisations. Work-related stress arises where work demands 
of various types and combinations exceed the person's capacity and capability to cope. Work-related stress is the second most common compensated illness/injury in Australia, after musculoskeletal disorders.

\section{Factors leading to work stress:}

The following factors, amongst others, can lead to work stress:

- Heavy workload

- Having little control or influence in decisions

- Tension or conflict with other employees

- Poor supervision or management

- Lack of belief in the objectives of the organisation

- Job insecurity or lack of opportunity to develop

- Lack of interest or fulfillment in the nature of the work

- Unpleasant or dangerous work environments

\section{Review of Literature}

Jeffrey M. Stanton had undergone a study on a General Measure of Work Stress. He study focused on the development and validation of scores on the Stress in General scale. Three diverse samples of workers $(\mathrm{n}=$ $4,322, \mathrm{n}=574, \mathrm{n}=34$ ) provided psychometric and validity evidence. All evidence converged on the existence of two distinct subscales, each of which measured a different aspect of general work stress. The studies also resulted in meaningful patterns of correlations with stressor measures, a physiological measure of chronic stress (blood-pressure reactivity), general job attitude measures, and intentions to quit.

Joseph Sharit has undertaken a study Occupational Stress. He focus on the measurement, sources, and management of stress, as well as the relationship between stress and coronary heart disease. Concepts related to stress (mental load, fatigue, and arousal) are defined and differentiated

Daniel C. Ganster and John Schaubroeck had undergone a research on Work Stress and Employee Health. They reviewed and summarized on the literature on work stress with particular emphasis on those studies that examined the effects of work characteristics on employee health. Although there is not convincing evidence that job stressors cause health effects, the indirect evidence is strongly suggestive of a work stress effect. This evidence comes from occupational studies that show differences in health and mortality that are not easily explained by other factors and within-subject studies that demonstrate a causal effect of work experiences on physiological and emotional responses. They argue that studies relying on self-report of working conditions and outcomes, whether cross-sectional or longitudinal, are unlikely to add significantly to the accumulated evidence. Finally, they make recommendations for how organizational researchers are most likely to contribute to this knowledge.

Gardner, Sallie has undergone a study Stress among Prospective Teachers on Student-teacher distress has the potential to impact on the individuals who are to become teachers, the profession and the education system. This review examines what is known of psychological distress among university students, teachers and student-teachers, the demands associated with their practical experiences and the known impact of psychological distress. A brief overview of contemporary stress management approaches is also presented. The reviewer contends that the potential problem for prospective teachers requires a holistic approach, beginning through understanding contemporary strategies available to individual university students, and preventative stress management programs provided within tertiary education, which may be made available to future studentteachers.

Sharron SK Leung has undergone Occupational stress, mental health status and stress management behaviors among secondary school teachers in Hong Kong. This study aimed to examine occupational stress and mental health among secondary school teachers in Hong Kong, and to identify the differences between those actively engaged in stress management behaviors and those who were not. Secondary teachers in Hong Kong have high occupational stress but insufficient stress coping resources. Cognitive-behavioral programs to enhance teachers' stress management resources are recommended.

Ravinder kaur has undergone a study on psycho-social problems of women teachers working in schools and colleges of Punjab. This paper is a study of the psycho-social problems of women teachers due to institution. Administrators, policymakers should help to create a work environment that conveys caring and promotes fairness. If employees feel that the work place climate supports balancing work and family responsibilities, they may experience higher levels of work/family enrichment as well as work and family 
satisfaction. Family support organizational policies may be designed to provide assistance to employees coping with psycho-social problems.

Objective of the study:

- To find opinion about teaching and handling students

- To find out the stress creators

- To analysis of sharing stress problems

- To find out techniques applied by the College teachers for managing stress.

\section{Research Methodology}

For the purpose of measuring the objectives following methodology is adopted.

\section{Sources of Data:}

Primary data- Through structured questionnaire designed on the basis of objectives of the study. The data was collected from 50 respondents.

Secondary data- Collected through various publications in management journals and internet which is restricted to the conceptual framework of the paper only.

Sample method: Simple random sampling method was used.

\section{Concept of Stress:}

Stress according to :

Physicists: A force, stress or pressure implying exposure to excessive demands or environmental conditions that cause emotional upset and tension.

Psychologists: Anything that alters the psychological homeostatic process.

Anthropologists: Is adversity; coercion between people, or between the environment and humans, or b between history and humankind.

Endocrinologists: Is the non-specific response of the body to any demand made on it.

\section{Stress Creator:}

Stress happen from two sources- external stress and internal stress.

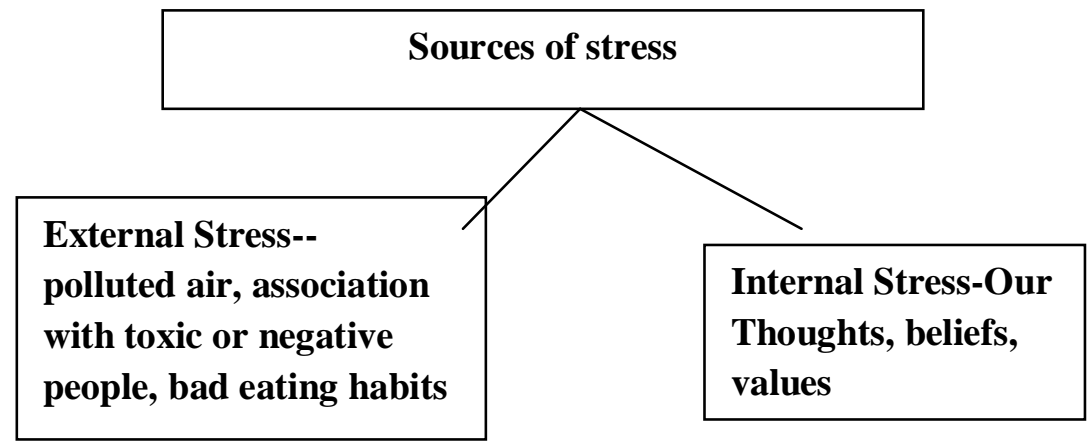

External stress is caused by external factors. The external stress factors are- polluted air that affects your body, association with toxic or negative people, people who are always thinking negatively, energy filed. Internal stress is caused by internal factors such as thoughts, beliefs and values,

\section{Stress Management Techniques:}

Stress Management can create success and cannot create failure.

\section{Relaxation training:}

It reduce heart rate, skin conductance, muscle tension, blood pressure, energy utilization, self-reports of anxiety, and tension.

\section{Ancillary skills:}

It helps to set specific work goals for each day, establish priorities, avoid timewasters, and learn what to ignore altogether. It concentrates time management and planning. 
III. Assertiveness training:

It helps to improve the creativity, boldness, self control and confident.
IV. ABCD Technique
A- Attitude
B- -Belief
C- Commitment
D- Devotion.

\section{Analysis and Interpretation}

Table No.:1 Opinion about teaching and handling students

\begin{tabular}{|l|c|c|}
\hline \multicolumn{1}{|c|}{ Opinion } & No. of Respondents & Percentage \\
\hline Strongly Satisfied & 17 & 34 \\
\hline Satisfied & 19 & 38 \\
\hline Neutral & 6 & 12 \\
\hline Dissatisfied & 6 & 12 \\
\hline Strongly dissatisfied & 2 & 4 \\
\hline Total & 50 & 100 \\
\hline
\end{tabular}

Source: Primary Data

The above table shows that opinion about the teaching and handling students. $38 \%$ of the College teachers were satisfied their work. $34 \%$ of College teachers were strongly satisfied. $12 \%$ of College teachers were neutral and dissatisfied about their works. Only $4 \%$ of College teachers were strongly dissatisfied about their works.

Table No.:2 Analysis of Stress Creator

\begin{tabular}{|l|c|c|}
\hline \multicolumn{1}{|c|}{ Opinion } & No. of Respondents & Percentage \\
\hline Poor student behaviour and results & 26 & 52 \\
\hline Management politics & 6 & 12 \\
\hline Interference of work with personal life & 14 & 28 \\
\hline Colleagues & 4 & 8 \\
\hline Total & 50 & 100 \\
\hline
\end{tabular}

Source: Primary Data

The table no. 2 reveals that analysis of stress creator. 52\% of College teachers were stressed through the poor student behavior and results. $12 \%$ of College teachers were stressed through the management politics. $28 \%$ were stressed in the interference of work with personal life. Only $8 \%$ of College teachers were stressed through their colleagues.

Table No.:3 Analysis of marital status

\begin{tabular}{|l|l|l|}
\hline Opinion & No. of Respondents & Percentage \\
\hline Unmarried & $\mathbf{2 5}$ & $\mathbf{5 0}$ \\
\hline Married & $\mathbf{2 2}$ & $\mathbf{4 4}$ \\
\hline Widowed & $\mathbf{2}$ & $\mathbf{4}$ \\
\hline Married and divorced/separated & $\mathbf{1}$ & $\mathbf{2}$ \\
\hline Total & $\mathbf{5 0}$ & $\mathbf{1 0 0}$ \\
\hline
\end{tabular}

Source: Primary Data

Table No.3 shows marital status of the researchers. 50\% of the College teachers were unmarried. $44 \%$ of the College teachers were married, $4 \%$ of the College teachers were widowed, and $2 \%$ of the College teachers were married and divorced/separated.

Table No.:4 Analysis of sharing stress problems

\begin{tabular}{|l|c|c|}
\hline \multicolumn{1}{|c|}{ Opinion } & No. of Respondents & Percentage \\
\hline Family & 5 & 10 \\
\hline Friends & 28 & 56 \\
\hline Colleagues & 15 & 30 \\
\hline None & 2 & 4 \\
\hline Total & 50 & 100 \\
\hline
\end{tabular}

Source: Primary Data

The table no. 4 reveals that opinion about the sharing stress problems. $56 \%$ of the College teachers were sharing stress problems with friends, $30 \%$ of the College teachers were sharing stress problems with colleagues, $10 \%$ of the College teachers were sharing stress problems with their family and only $4 \%$ of the College teachers were not shared the stress problems. 
Table No.:5 Analysis of managing stress

\begin{tabular}{|l|c|c|}
\hline \multicolumn{1}{|c|}{ Opinion } & No. of Respondents & Percentage \\
\hline Rest & 5 & 10 \\
\hline Coffee & 10 & 20 \\
\hline Reading Books & 15 & 30 \\
\hline Listening Music's & 9 & 18 \\
\hline Yoga and Meditation & 9 & 18 \\
\hline Exercise & 2 & 4 \\
\hline Total & 50 & 100 \\
\hline
\end{tabular}

Source: Primary Data

The table no. 5 indicates that managing stress techniques. $30 \%$ of the College teachers were reading books, $20 \%$ of the college teachers were taken coffee, $18 \%$ of the college teachers were listen music's, $18 \%$ of the college teachers were undertake yoga and meditation, $10 \%$ of the college teachers were taken rest, and only $4 \%$ of the college teachers were exercised for managing stress.

\section{Findings:}

- External factors create lot of stress among the college teachers.

- $38 \%$ of the College teachers were satisfied their work.

- $52 \%$ of College teachers were stressed through the poor student behavior and results.

- $50 \%$ of the College teachers were unmarried.

- $56 \%$ of the College teachers were sharing stress problems with friends.

- $30 \%$ of the College teachers were reading books for managing stress.

\section{Conclusion}

The college teachers having lot of work stress due to their work, and students performance. Majority of the teachers share their problems with friends. The stress can not be avoided, so it should be managed with the proper usage of management techniques. Mainly in rural area the college teachers should use lot of techniques for managing stress like yoga, meditation, listening music's, reading books and rest. Stress Management is the important techniques it is used depends upon their work schedule.

\section{Books:}

\section{Bibliography}

[1]. Ajay Shukla, Stress Management, $2^{\text {nd }}$ Edition, Unicorn Books Pvt. Ltd., New Delhi

[2]. Beck,CJ,Nothing Special:Living Zen,San Francisco:Harper San Francisco,1993

[3]. Neil Nievn, Health Psychology, $2^{\text {nd }}$ Edition, Churchill Livingstone, London.

[4]. Shelley E.Taylor, Health Psychology, $3^{\text {rd }}$ Edition. McGraw Hill Internnational Editions, 1995.

[5]. Swami Sukhabodhananda,Stress Management-Fourth Edition, Sudhindra Malleswaram, Bangalore

[6]. Swaminathan, V.D.Latha Sathish, Psychology for Effective Living, Departmet of Psychology, University of Madras

[7]. Taimini.l.k.(1973) Glimpses into the Pshychology of Yoga- The Theorsophical Publication House, Chennai.

[8]. Umesh Sharma, Stress Management, First Edition, Excel Books - New Delhi.

\section{Journals:}

[9]. Daniel C. Ganster and John Schaubroeck,(June 1991), Journal of Management, vol. 17 no. 2, pp - $235-271$.

[10]. Gardner, Sallie, ( Dec 2010),Australian Journal of Teacher Education, vol 35, no.8, pp -18-28.

[11]. Jeffrey M. Stanton, ( October 2001), Educational and Psychological Measurement, vol. 61, no. 5, pp - 866-888.

[12]. Joseph Sharit, (April 1982), The Journal of the Human Factors and Ergonomics Society, vol. 24, no. 2, pp - 129-162.

[13]. Sharron SK Leungdoi, December 2009, Health Education Journal, vol. 68, no. 4, pp - 328-343

[14]. Website:

[15]. www.ejournal.aiaer.net/vol22110/2.Kaur\%20...pdf

[16]. www.betterhealth.via.gov.au

[17]. http://www.apa.org/topics/stress/ 